\title{
Developing a Platform for Chronic Diseases Awareness
}

\author{
Nada Abdullah Alqarni, Shahad Saeed Alqahtani, Sara Ahmed Alhumaidi, Ibtihaj Mohammed Almutairi, \\ Muneerah Alshabanah, Daniah Alrajhi, Mutasem K. Alsmadi and Ibrahim Almarashdeh
}

Department of Management Information Systems, College of Applied Studies and Community Service, Imam Abdulrahman Bin Faisal University, Dammam, Saudi Arabia

\begin{abstract}
The increasing chronic disease's epidemic is due to alcohol, smoking, lack of physical activity, obesity and unhealthy diet causing common diseases such as hypertension, osteoporosis, stroke, myocardial infarction renal insufficiency and diabetes. Preventive action against such diseases could be to improve health awareness through the use of health awareness platforms supporting behavior change and self-observation. Policy-makers play a vital role in decreasing the burden and risk of chronic diseases through implementing programs and policies that improve access to healthcare and provide a healthy environment. An official planning framework and national policy are crucial to give chronic diseases proper priority and to arrange resources properly. This work aims to design and develop a platform for chronic disease awareness. The proposed system was developed using the Unified Modeling Language (UML), ASP.NET, HTML and CSS.
\end{abstract}

Keywords : Health, Chronic Diseases, Platform, Unified Modeling Language.

\section{INTRODUCTION}

Throughout the last years, many mobile and web applications have been developed aiming to support self-care and improve health awareness. Most of them were proposed to be used by patients with chronic diseases, another goal is to motivate their users to a healthier and better lifestyle which can also be applied to young, healthy persons. These applications used various technologies ranged from web applications and web services using RIA (rich internet application) approaches to client-side technologies such as native client device applications and the Java2 Micro Edition (J2ME) [1-4].

Personal Health Applications (PHAs) enable the user to store and manage their personal health information, thus helping patients and assisting the information flow between patients and health care providers. Besides the personal data of the users, the application is able to store a variety of data related to health like laboratory test results, medical conditions, allergies, and medications. these applications include LifeSensor, Microsoft HealthVault, or Google Health. Microsoft's solution makes an effort on connecting to external health devices such as pedometers, glucometers and blood pressure monitors. The key strengths of Google Health are its capability of connecting to external health providers such as hospitals as well as the ability for external applications for accessing functions of Google Health by the Health Data API [1-4].

The Internet is being used as a source of health and medical information on a large scale by millions of people around the world. A recent scientific study in 
Saudi Arabia showed that only a small number of Arab health sites achieve international quality standards for health sites. This means that Arab users of the internet will not always succeed in finding reliable health information in Arabic, and maybe victims of misinformation presented in forums and social networking sites [5]. Moreover; most of the available web and mobile health-supporting applications do not aim to support healthy persons in their daily healthy activities and only support people recovering from certain illnesses and people with chronic diseases. Regardless of the different goals such as patient motivation and empowerment and target groups, are largely the same [1-4]. This work aims to design and develop a platform for chronic disease awareness.

\section{Related Works}

King Abdullah Arabic Health Encyclopedia (KAAHE) aims to be the first website to provide reliable health information in Arabic. The KAAHE provide reliable health information to the Arab reader in an easy and simple way to increase health awareness and support the efforts of various health facilities in promoting the health of citizens. Figure 1 shows the main interface for KAAHE website.

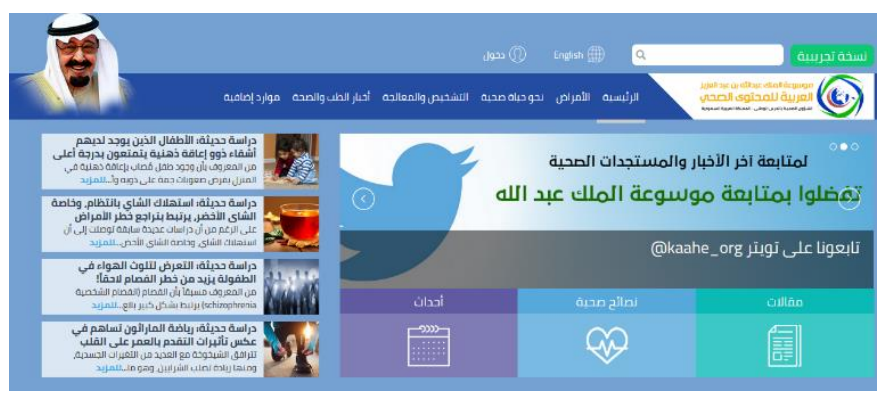

Figure $1:$ The main interface for KAAHE website.

WebTeb works to provide trusted medical and health information to arabic readers wherever they are. We believe in everyone's right to knowledge and easy access to trusted information. WebTeb, through its website, social media portals and applications, aims to be a comprehensive platform for communication between arab citizens and health care providers, such as doctors, clinics, hospitals, pharmacies, pharmaceutical and insurance companies, medical associations and organizations working in health education and awareness, and any other entity working to improve the health of Arabic speaking citizens within the ethical and professional standards of WebTeb. Figure 2 shows the main interface for WebTeb website.

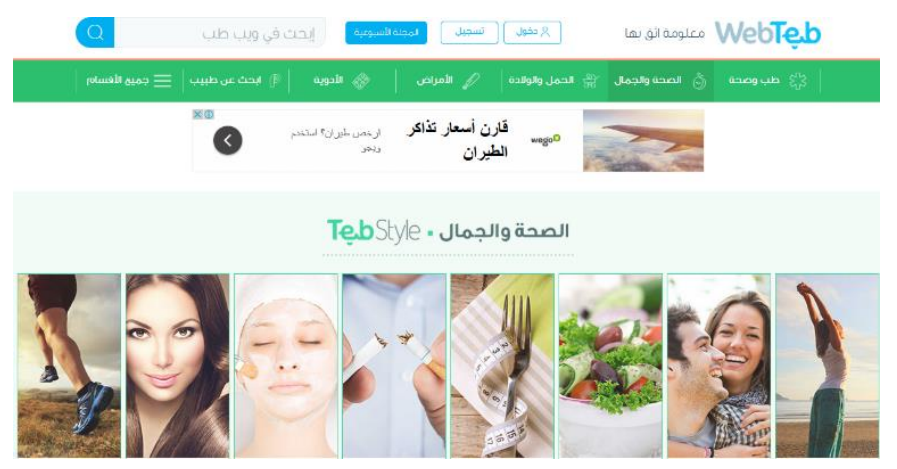

Figure 2 : The main interface for WebTeb website.

World Health Organization (WHO) aims to build a healthier, better future for the public around the world. WHO Works with 194 countries, across six regions, and has near 150 offices, WHO staff are committed to achieving improved health for everybody, everywhere. WHO works to strive to combat diseases - infectious diseases like HIV and influenza, and non-infectious diseases like heart disease and cancer. They help children and mothers to survive so they live healthier for old age. Figure 3 shows the main interface for the WHO website and figure 4 shows the WHO Regional websites. 


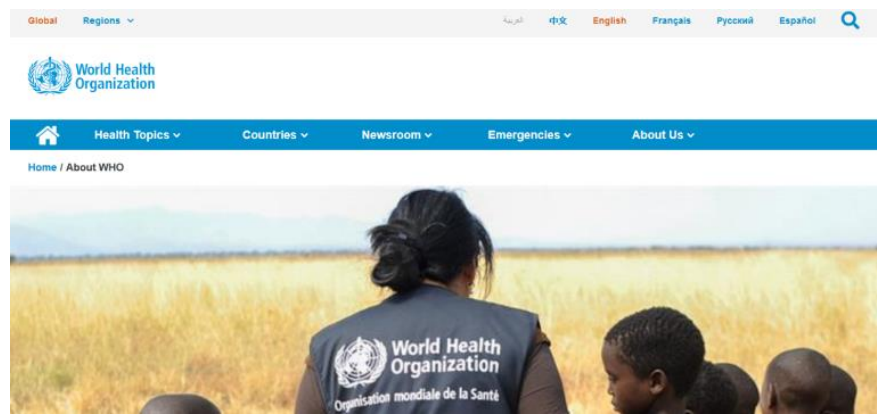

Figure 3 : The main interface for WHO website.

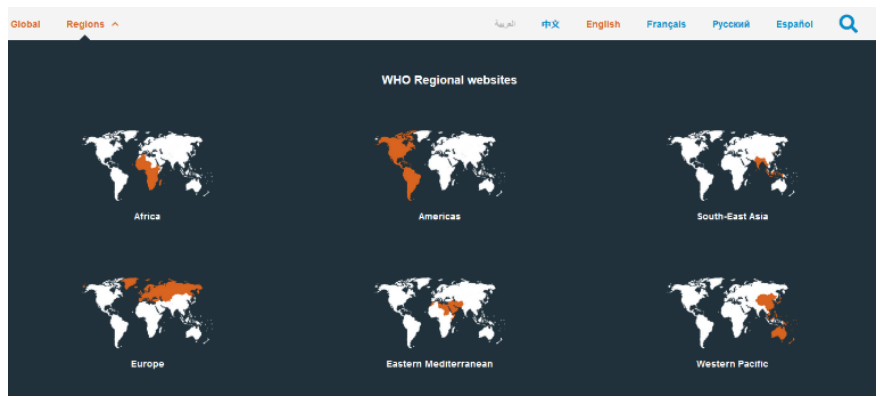

Figure 4: WHO Regional websites.

The technological revolution influenced everything [6-83], even the methods that aim to improve the community culture and knowledge by developing tools for chronic diseases awareness within the community through a free electronic application. Today, the use of Artificial Intelligence (AI) algorithms is expansive, particularly in providing solutions to challenging problems including image segmentation [7], image classification and retrieval of information [53], as well as Healthcare Monitoring system [46, 57]. Accordingly, many researchers have used $\mathrm{AI}$ as an effective tool for developing applications for chronic diseases awareness $[84,85]$.

\section{METHODOLOGY}

The process systems analysis includes gathering and interpreting evidence, problems identifying and decomposing the system into its elements.
Unified Modeling Language (UML), is a standardized modeling language containing a set of diagrams that are integrated, established for helping software and system developers for specifying, constructing, visualizing, and documenting the software artifacts, in addition to other non-software systems and business modeling. The UML depicts the best engineering practices which are demonstrated successful modeling of complex and large systems. UML is a key component of the object-oriented software development process. The UML utilizes graphical notations for expressing the software design [86-90]. The Use-case diagram and the Context diagram are addressed below.

\subsection{Use Case Diagram}

In UML, the use case diagram is a behavior or dynamic diagram. Use case diagrams model the system's functionality using use cases and actors. Use cases are a set of functions, services, and actions that the system has to perform. In this context, a "system" is something being operated or developed, for example, a web site $[19,67,89,91,92]$. The entities or people operating under specified roles within the system are the actors. Figure 5 demonstrates the proposed system's use case diagram.

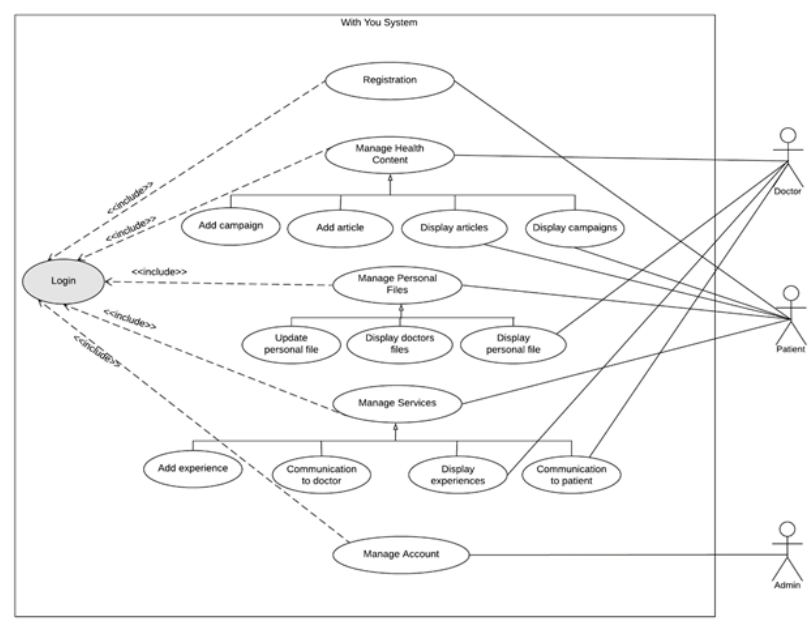

Figure 5: Use case diagram for the proposed system. 


\subsection{Context Diagram}

Context Diagram (CD) is a model that demonstrates the product interaction with outside people, systems, and/or organizations. The context diagram assists in identifying the interfaces needed to account, identifying the potential stakeholders, identifying the scope, and understanding the context in which you are working in a better way[93]. Figure 6 shows the Context Diagram for the proposed system.

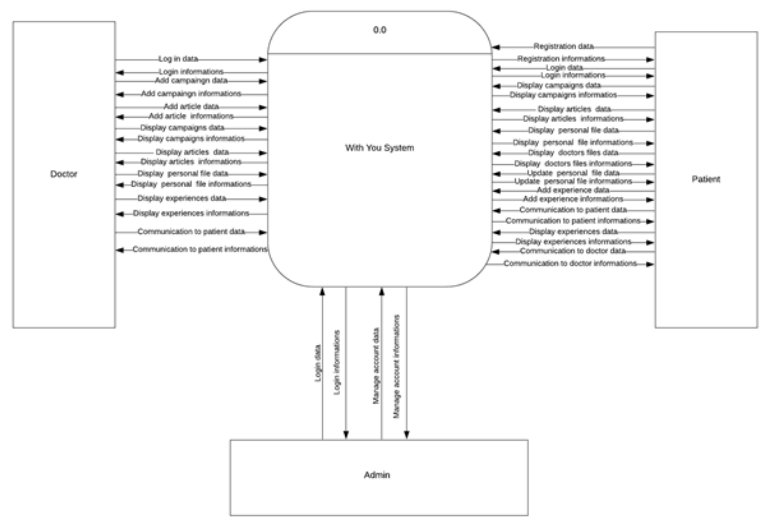

Figure 6 : The Context Diagram for the proposed system.

\subsection{Entity Relationship (ER) Diagram}

The ER Diagram is a flowchart shows the way that entities such as people, objects, or concepts are related to each other within a system. ER Diagrams are usually used to design or debug relational databases in research and education, software engineering and business information systems [94, 55, 54, 45, 44]. ER diagrams are related to Data Structure Diagrams (DSDs), which focusses on within entities elements' relationships rather than the relationships among entities themselves. Also, ER diagrams are usually utilized with data flow diagrams (DFDs), which describe the flow of information for processes or systems. Figure 7 illustrates the proposed system's ER diagram.

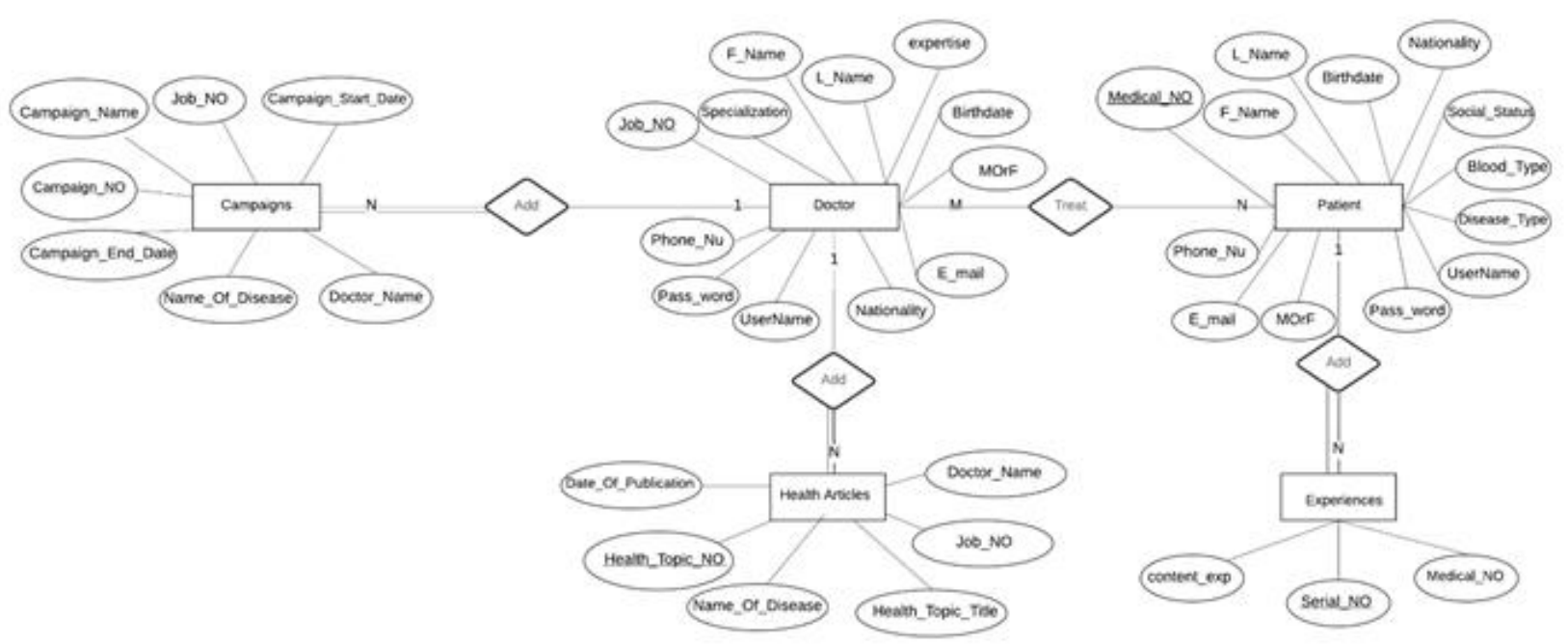

Figure 7 : ER diagram for the proposed system.

\subsection{Interface Design}

The design of the user interface (UI) is the process of creating interfaces in computerized devices or software while focusing on style or looks. Software designers aim to make pleasurable and easy to use designs. UI design mainly denotes the graphical interfaces, it also comprises others, such as voice- controlled interfaces. ASP.NET is the programming language that was utilized in this work. The user starts in the proposed system with the registration; then the user has to fill a login form with the information required. If the entered information, by the system search in the database, was found correct the system homepage will be shown to the user and allows him to use the proposed system. if it's not 
correct, the system will redirect the user to the login page. The figures below show examples of the interfaces that were designed and implemented.
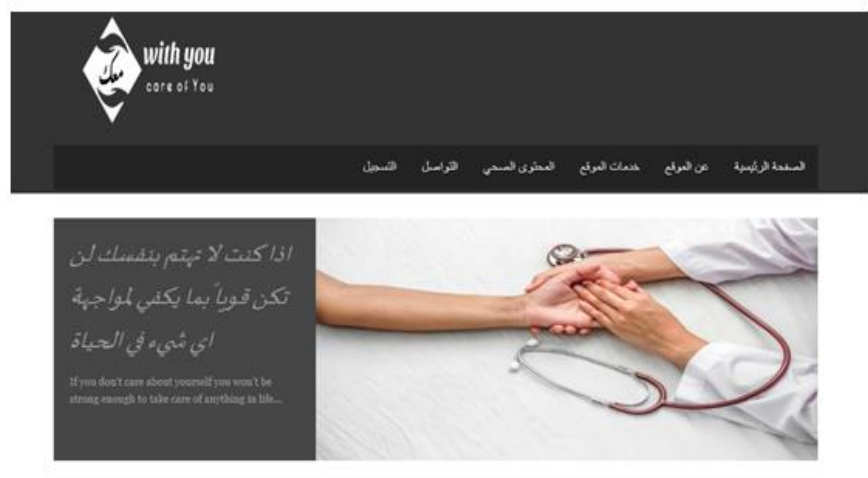

الحماتحا

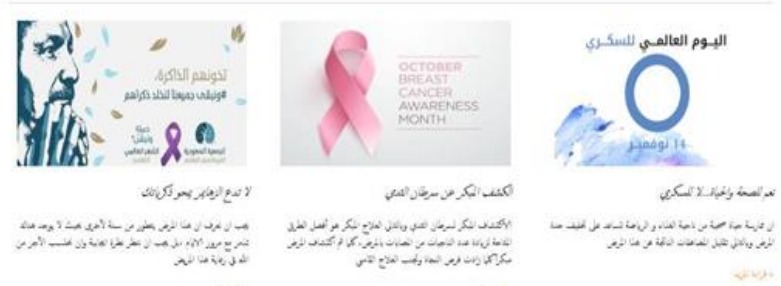

Figure 8: Main interface.
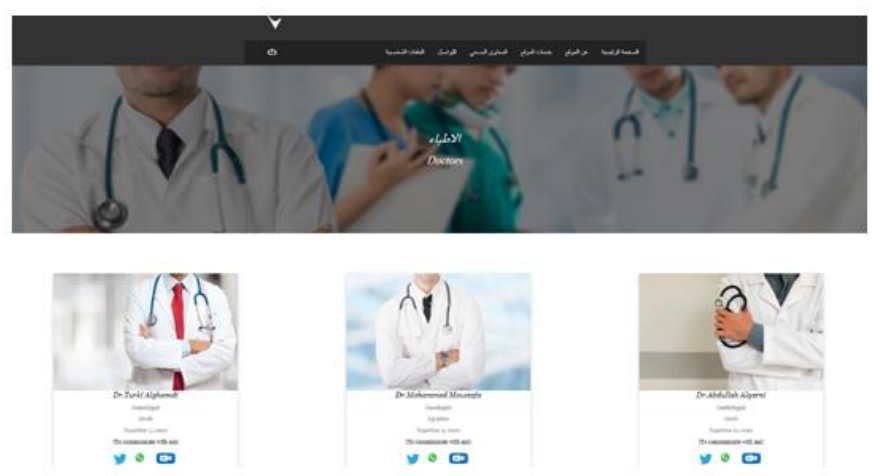

Figure 9: Participant doctors interface

\section{DISCUSSION}

The proposed system's usability is highlighted in this step. The system is evaluated during this stage while the satisfaction of the user is ensured. The proposed system was tested by running it on Internet Explorer and Mozilla Firefox using the localhost server. To evaluate the system, 20 students from the Imam Abdurrahman Bin Faisal University (IAU), College of Applied Studies and Community Service were invited to use the prototype. The students were first briefed on the usage of the user interface and the prototype. Then, the students tried the system and answered the 10 items questionnaire formulated to asses the level of user satisfaction. Also, the proposed system's usability was determined. Figure 10 illustrates the level of usability of the system according to the 20 students' feedback. As can be seen in the result, a high percentage of users agree that the system is useful, practical and fulfill the primary objective of the project.

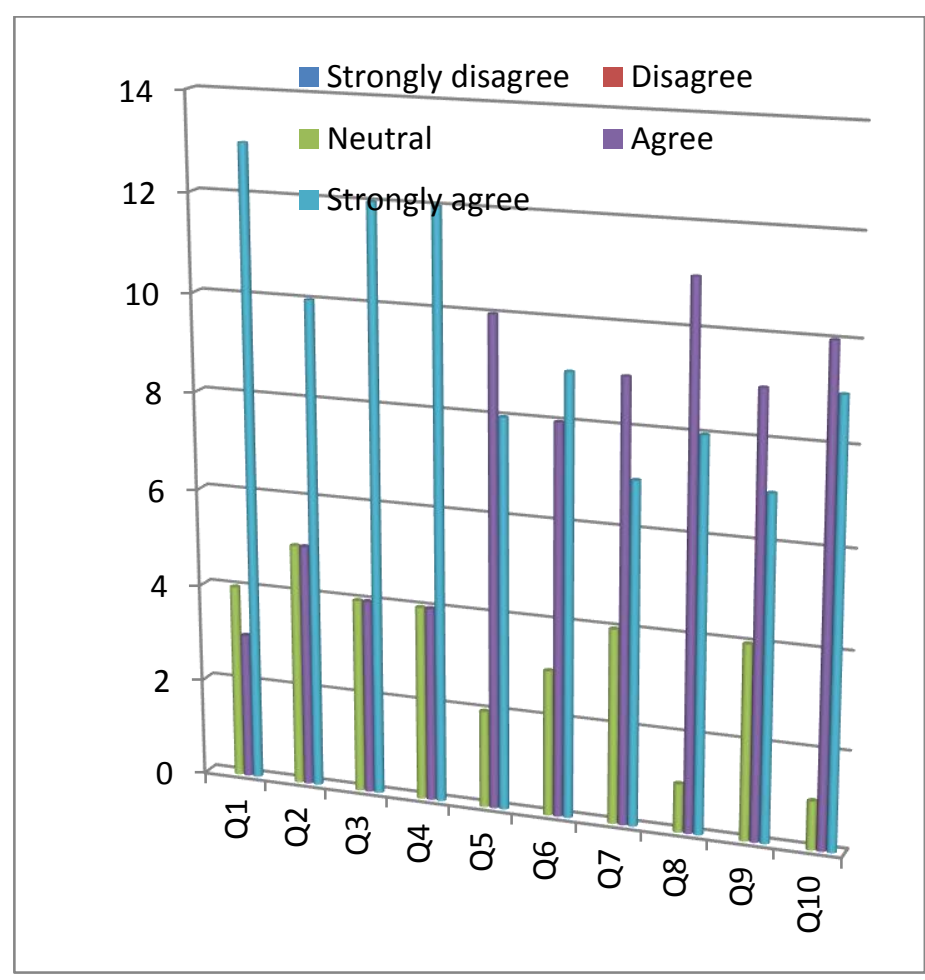

Figure 10: collected data results from the 20 students.

\section{CONCLUSION}

This paper highlights the best practices in designing and building a web platform for chronic diseases awareness. The platform aims to provide preventive action against such diseases which could improve health awareness through the use of health awareness platforms supporting behavior change and selfobservation. Policy-makers play a vital role in decreasing the burden and risk of chronic diseases 
through implementing programs and policies that improve access to healthcare and provide a healthy environment. The proposed system was developed using Unified Modeling Language (UML), ASP.NET, HTML and CSS.Arduino

\section{REFERENCES}

[1]. A. Holzinger, S. Dorner, M. Födinger, A. C. Valdez, and M. Ziefle, "Chances of increasing youth health awareness through mobile wellness applications," in Symposium of the Austrian HCI and Usability Engineering Group, 2010, pp. 7181.

[2]. R. M. M. Creber, M. S. Maurer, M. Reading, G. Hiraldo, K. T. Hickey, and S. Iribarren, "Review and analysis of existing mobile phone apps to support heart failure symptom monitoring and self-care management using the Mobile Application Rating Scale (MARS)," JMIR mHealth and uHealth, vol. 4, p. e74, 2016.

[3]. A. Sunyaev and D. Chornyi, "Supporting chronic disease care quality: design and implementation of a health service and its integration with electronic health records," Journal of Data and Information Quality (JDIQ), vol. 3, p. 3, 2012.

[4]. M. Rebhan, "Towards a systems approach for chronic diseases, based on health state modeling," F1000Research, vol. 6, 2017.

[5]. KAAHE, "King Abdullah Arabic Health Encyclopedia," https://kaahe.org/enus/Pages/Footer/AbouttheEncyclopedia.aspx. Access 16-1-2020].

[6]. I. Almarashdeh and M. K. Alsmadi, "How to make them use it? Citizens acceptance of Mgovernment," Applied Computing and Informatics.

[7]. M. Alsmadi, K. Omar, S. Noah, I. Almarashdeh, S. Al-Omari, P. Sumari, S. Al-Taweel, A. Husain, N. Al-Milli, and M. Alsmadi, "Fish recognition based on robust features extraction from size and shape measurements using neural network," Information Technology Journal, vol. 10, pp. 427-434, 2009.

[8]. M. Alsmadi, K. B. Omar, and S. A. Noah, "Back propagation algorithm: the best algorithm among the multi-layer perceptron algorithm," International Journal of Computer Science and Network Security, vol. 9, pp. 378-383, 2009.

[9]. M. k. Alsmadi, K. B. Omar, and S. A. Noah, "Proposed method to decide the appropriate feature set for fish classification tasks using Artificial Neural Network and Decision Tree," IJCSNS vol. 9, pp. 297-301, 2009.

[10]. M. K. S. Alsmadi, K. B. Omar, S. A. Noah, and I. Almarashdah, "Fish recognition based on the combination between robust feature selection, image segmentation and geometrical parameter techniques using Artificial Neural Network and Decision Tree," arXiv preprint arXiv:0912.0986, 2009.

[11]. M. khalil Alsmadi, K. B. Omar, S. A. Noah, and I. Almarashdah, "Performance comparison of multi-layer perceptron (Back Propagation, Delta Rule and Perceptron) algorithms in neural networks," in 2009 IEEE International Advance Computing Conference, 2009, pp. 296-299.

[12]. I. A. Almarashdeh, N. Sahari, N. A. M. Zin, and M. Alsmadi, "THE SUCCESS OF LEARNING MANAGEMENT SYSTEM AMONG DISTANCE LEARNERS IN MALAYSIAN UNIVERSITIES," Journal of Theoretical \& Applied Information Technology, vol. 21, 2010.

[13]. I. A. Almrashdah, N. Sahari, N. A. H. M. Zin, and M. Alsmadi, "Instructors acceptance of distance learning management system," in Information Technology (ITSim), 2010 International Symposium in, 2010, pp. 1-6.

[14]. I. A. Almrashdah, N. Sahari, N. A. H. M. Zin, and M. Alsmadi, "Distance learners acceptance of learning management system," in Advanced Information Management and Service (IMS), 
2010 6th International Conference on, 2010, pp. 304-309.

[15]. M. K. Alsmadi, K. B. Omar, and S. A. Noah, "Fish recognition based on robust features extraction from size and shape measurements using backpropagation classifier," International Review on Computers and Software, vol. 5, pp. 489-494, 2010.

[16]. M. K. Alsmadi, K. B. Omar, S. A. Noah, and I. Almarashdeh, "Fish recognition based on robust features extraction from color texture measurements using back-propagation classifier," Journal of Theoritical and Applied Information Technology, vol. 18, 2010.

[17]. M. K. Alsmadi, K. B. Omar, S. A. Noah, and I. Almarashdeh, "Fish recognition based on robust features extraction from size and shape measurements using neural network," Journal of Computer Science, vol. 6, p. 1088, 2010.

[18]. I. A. Almarashdeh, N. Sahari, N. A. M. Zin, and M. Alsmadi, "Acceptance of learning management system: A comparison between distance learners and instructors," Advances in Information Sciences and Service Sciences, vol. 3, pp. 1-9, 2011.

[19]. I. A. ALMRASHDEH, N. SAHARI, N. A. M. ZIN, and M. ALSMADI, "DISTANCE LEARNING MANAGEMENT SYSTEM REQIUREMENTS FROM STUDENT'S PERSPECTIVE," Journal of Theoretical \& Applied Information Technology, vol. 24, 2011.

[20]. I. A. Almrashdeh, N. Sahari, N. A. M. Zin, and M. Alsmadi, "Instructor's success measures of Learning Management System," in Electrical Engineering and Informatics (ICEEI), 2011 International Conference on, 2011, pp. 1-7.

[21]. I. A. Almrashdeh, N. Sahari, N. A. M. Zin, and M. Alsmadi, "Requirement analysis for distance learning management system students in Malaysian universities," Journal of Theoretical and Applied Information Technology, vol. 24, pp. 17-27, 2011.

[22]. M. Alsmadi, K. Omar, S. Noah, and I. Almarashdeh, "A hybrid memetic algorithm with back-propagation classifier for fish classification based on robust features extraction from PLGF and shape measurements," Information Technology Journal, vol. 10, pp. 944-954, 2011.

[23]. M. K. Alsmadi, K. B. Omar, and S. A. Noah, "Fish classification based on robust features extraction from color signature using back-propagation classifier," Journal of Computer Science, vol. 7, p. 52, 2011.

[24]. M. Alsmadi, K. Omar, and I. Almarashdeh, Fish Classification: Fish Classification Using Memetic Algorithms with Back Propagation Classifier: LAP Lambert Academic Publishing, 2012.

[25]. M. Alsmadi, U. A. Badawi, and H. E. Reffat, "A High Performance Protocol for Fault Tolerant Distributed Shared Memory (FaTP)," Journal of Applied Sciences, vol. 13, pp. 790-799, 2013.

[26]. M. Alsmadi, U. A. Badawi, H. E. Reffat, S. Qiang, F. Chanjian, L. Yuegang, and S. Peng, "Faults Diagnosis for Automotive Engine Based on Chinin," Journal of Applied Sciences, vol. 13, p. 5632, 2013.

[27]. U. A. Badawi and M. K. S. Alsmadi, "A Hybrid Memetic Algorithm (Genetic Algorithm and Great Deluge Local Search) With BackPropagation Classifier for Fish Recognition " International Journal of Computer Science Issues, vol. 10, pp. 348-356, 2013.

[28].Z. Thalji and M. Alsmadi, "Iris Recognition using robust algorithm for eyelid, eyelash and shadow avoiding," World Applied Sciences Journal, vol. 25, pp. 858-865, 2013.

[29]. M. K. Alsmadi, "A hybrid firefly algorithm with fuzzy-C mean algorithm for MRI brain segmentation," American Journal of Applied Sciences, vol. 11, pp. 1676-1691, 2014. 
[30].M. K. Alsmadi, U. A. Badawi, and H. M. Moharram, "SERVER FAILURES ENABLED JAVASPACES SERVICE," Journal of Computer Science, vol. 10, pp. 671-679, 2014.

[31].U. A. Badawi and M. K. Alsmadi, "A GENERAL FISH CLASSIFICATION METHODOLOGY USING META-HEURISTIC ALGORITHM WITH BACK PROPAGATION CLASSIFIER," Journal of Theoretical \& Applied Information Technology, vol. 66, pp. 803-812, 2014.

[32]. A. M. Al Smadi, M. K. Alsmadi, H. Al Bazar, S. Alrashed, and B. S. Al Smadi, "Accessing Social Network Sites Using Work Smartphone for Face Recognition and Authentication," Research Journal of Applied Sciences, Engineering and Technology, vol. 11, pp. 56-62, 2015.

[33]. M. K. Alsmadi, "MRI brain segmentation using a hybrid artificial bee colony algorithm with fuzzy-c mean algorithm," Journal of Applied Sciences, vol. 15, p. 100, 2015.

[34].F. HADDAD, J. ALFARO, and M. K. ALSMADI, "HOTELLING'S T ${ }^{2}$ CHARTS USING WINSORIZED MODIFIED ONE STEP MESTIMATOR FOR INDIVIDUAL NON NORMAL DATA," Journal of Theoretical \& Applied Information Technology, vol. 72, pp. 215-226, 2015.

[35].I. Almarashdeh and M. Alsmadi, "Investigating the acceptance of technology in distance learning program," in 2016 International Conference on Information Science and Communications Technologies (ICISCT), 2016, pp. 1-5.

[36].I. Almarashdeh and M. Alsmadi, "Heuristic evaluation of mobile government portal services: An experts' review," in Internet Technology and Secured Transactions (ICITST), 2016 11th International Conference for, 2016, pp. 427-431.

[37]. M. Alsmadi, "Facial recognition under expression variations," Int. Arab J. Inf. Technol., vol. 13, pp. 133-141, 2016.
[38]. M. K. Alsmadi, "Forecasting River Flow in the USA Using a Hybrid Metaheuristic Algorithm with Back-Propagation Algorithm," Scientific Journal of King Faisal University (Basic and Applied Sciences), vol. 18, pp. 13-24, 2017.

[39].M. K. Alsmadi, "Query-sensitive similarity measure for content-based image retrieval using meta-heuristic algorithm," Journal of King Saud University - Computer and Information Sciences, 2017/05/13/ 2017.

[40].M. K. Alsmadi, "An efficient similarity measure for content based image retrieval using memetic algorithm," Egyptian Journal of Basic and Applied Sciences, vol. 4, pp. 112-122, 2017/06/01/ 2017.

[41].M. K. Alsmadi and U. A. Badawi, "Pattern matching in Rotated Images Using Genetic Algorithm," Journal of King Abdulaziz University Computing and Information vol. 5, pp. 53 - 59, 2017.

[42]. M. K. Alsmadi, A. Y. Hamed, U. A. Badawi, I. Almarashdeh, A. Salah, T. H. Farag, W. Hassan, G. Jaradat, Y. M. Alomari, and H. M. Alsmadi, "FACE IMAGE RECOGNITION BASED ON PARTIAL FACE MATCHING USING GENETIC ALGORITHM," SUST Journal of Engineering and Computer Sciences (JECS), vol. 18, pp. 5161, 2017.

[43]. T. H. Farag, W. A. Hassan, H. A. Ayad, A. S. AlBahussain, U. A. Badawi, and M. K. Alsmadi, "Extended Absolute Fuzzy Connectedness Segmentation Algorithm Utilizing Region and Boundary-Based Information," Arabian Journal for Science and Engineering, pp. 1-11, 2017.

[44]. R. Aldaej, L. Alfowzan, R. Alhashem, M. K. Alsmadi, I. Al-Marashdeh, U. A. Badawi, M. Alshabanah, D. Alrajhi, and M. Tayfour, "Analyzing, Designing and Implementing a Web-Based Auction online System," International Journal of Applied Engineering Research, vol. 13, pp. 8005-8013, 2018. 
[45].H. Almaimoni, N. Altuwaijri, F. Asiry, S. Aldossary, M. Alsmadi, I. Al-Marashdeh, U. A. Badawi, M. Alshabanah, and D. Alrajhi, "Developing and Implementing WEB-based Online Destination Information Management System for Tourism," International Journal of Applied Engineering Research, vol. 13, pp. 75417550, 2018.

[46].i. Almarashdeh, M. K. Alsmadi, T. Farag, A. S. Albahussain, U. A. Badawi, N. Altuwaijri, H. Almaimoni, F. Asiry, S. Alowaid, M. Alshabanah, D. Alrajhi, A. A. Fraihet, and G. Jaradat, "RealTime Elderly Healthcare Monitoring Expert System Using Wireless Sensor Network " International Journal of Applied Engineering Research, vol. 13, pp. 3517-3523, 2018.

[47]. I. Almarashdeh, M. K. Alsmadi, G. Jaradat, A. Althunibat, S. A. Albahussain, Y. Qawqzeh, U. A. Badawi, T. Farag, and K. E. Eldaw, "Looking Inside and Outside the System: Examining the Factors Influencing Distance Learners Satisfaction in Learning Management System " Journal of Computer Science, 2018.

[48]. I. Almarashdeh, K. E. Eldaw, M. AlSmadi, U. Badawi, F. Haddad, O. A. Abdelkader, G. Jaradat, A. Alkhaldi, and Y. Qawqzeh, "Search Convenience and Access Convenience: The Difference Between Website Shopping and Mobile Shopping," in International Conference on Soft Computing and Pattern Recognition, 2018, pp. 33-42.

[49]. I. Al-Marashdeh, G. M. Jaradat, M. Ayob, A. Abu-Al-Aish, and M. Alsmadi, "An Elite PoolBased Big Bang-Big Crunch Metaheuristic for Data Clustering," Journal of Computer Science, vol. 14, pp. 1611-1626, 2018.

[50].M. K. Alsmadi, "Apparatus and method for lesions segmentation," ed: US Patent App. 15/614,893, 2018.

[51].M. K. Alsmadi, "Facial expression recognition," ed: Google Patents, 2018.
[52].M. K. Alsmadi, "A hybrid Fuzzy C-Means and Neutrosophic for jaw lesions segmentation," Ain Shams Engineering Journal, vol. 9, pp. 697-706, 2018/12/01/ 2018.

[53].M. K. Alsmadi, "Query-sensitive similarity measure for content-based image retrieval using meta-heuristic algorithm," Journal of King Saud University-Computer and Information Sciences, vol. 30, pp. 373-381, 2018.

[54]. N. Alsubaie, N. Althaqafi, E. Alradwan, F. AlHazza, M. Alsmadi, I. Al-Marashdeh, U. A. Badawi, M. Alshabanah, D. Alrajhi, S. Alsmadi, and M. Tayfour, "Analyzing and Implementing an Online Metro Reservation System," International Journal of Applied Engineering Research, vol. 13, pp. 9198-9206, 2018.

[55].D. A. Daniyah Alkhaldi, Hajer Aldossary, Mutasem k. Alsmadi, Ibrahim Al-Marashdeh, Usama A Badawi, Muneerah Alshabanah, Daniah Alrajhi, "Developing and Implementing Webbased Online University Facilities Reservation System," International Journal of Applied Engineering Research, vol. 13, pp. 6700-6708, 2018.

[56].F. Haddad and M. K. Alsmadi, "Improvement of The Hotelling's T2 Charts Using Robust Location Winsorized One Step M-Estimator (WMOM)," Journal of Mathematics (ISSN 1016-2526), vol. 50, pp. 97-112, 2018.

[57]. M. Rasmi, M. B. Alazzam, M. K. Alsmadi, I. A. Almarashdeh, R. A. Alkhasawneh, and S. Alsmadi, "Healthcare professionals' acceptance Electronic Health Records system: Critical literature review (Jordan case study)," International Journal of Healthcare Management, pp. 1-13, 2018.

[58].A. A. Abbas, K. Alzayer, A. Alkhaldi, M. k. Alsmadi, M. Alshabanah, D. Alrajhi, I. Almarashdeh, and M. Tayfour, "Analyzing and Implementinga System For Reporting, Follow Up and Resolving of Complaints," International 
Research Journal of Engineering and Technology, vol. 6, pp. 1833-1842, 2019.

[59].A. O. Ahmed, M. E. Ahmed, M. M. E. Mekebbaty, A. M. Osman, A. S. Mohamed, G. M. Alhaj, and O. S. Shidwan, "Impact of Change Characteristics in Planning for Future Professional Career," International Journal of Applied Engineering Research, vol. 14, pp. 38693878, 2019.

[60]. S. Aldossary, A. Althawadi, M. Almotairy, M. k. Alsmadi, D. Alrajhi, M. Alshabanah, I. AlMarashdeh, M. Tayfour, and R. Aljamaeen, "ANALYZING, DESIGNING AND IMPLEMENTING A WEB-BASED COMMAND CENTER SYSTEM," International Research Journal of Engineering and Technology, vol. 6, pp. 1008-1019, 2019.

[61].A. Al-Ghamdi, D. Al Harbi, N. Alarfaj, A. Al Hajri, I. Almarashdeh, M. Alsmadi, M. Alshabanah, and D. Alrajhi, "Developing and Implementing a Web-Based Platform for Skills and Knowledge Exchange," Int J Sci Res Sci Technol, vol. 6, pp. 562-573, 2019.

[62].A. Al-Ghamdi, D. A. Harbi, N. Alarfaj, B. A. Hajri, I. Almarashdeh, M. k. Alsmadi, M. Alshabanah, and D. Alrajhi, "Developing and Implementing a Web-Based Platform for Skills and Knowledge Exchange," International Journal of Scientific Research in Science and Technology (IJSRST), vol. 6, 2019.

[63]. R. Alhafi, S. Almutairi, N. Alsultan, M. K. Alsmadi, M. Alshabanah, D. Alrajhi, and I. Almarashdeh, "E-Payment and Transactions using QR Codes," 2019.

[64].S. Alharbi, A. Altamimi, F. Al-Qahtani, B. Aljofi, M. Alsmadi, M. Alshabanah, D. Alrajhi, and I. Almarashdeh, "Analyzing and Implementing a Mobile Reminder System for Alzheimer's Patients," International Research Journal of Engineering and Technology, vol. 6, pp. 1-11, 2019.
[65].S. A. S. Ali, K. E. H. I. Eldaw, M. K. Alsmadi, and I. Almarashdeh, "Determinants of deposit of commercial banks in Sudan: an empirical investigation (1970-2012)," International Journal of Electronic Finance, vol. 9, pp. 230-255, 2019.

[66]. I. Almarashdeh, G. Jaradat, A. Abuhamdah, M. Alsmadi, M. B. Alazzam, R. Alkhasawneh, and I. Awawdeh, "The Difference Between Shopping Online Using Mobile Apps and Website Shopping: A Case Study of Service Convenience," International Journal of Computer Information Systems and Industrial Management Applications, vol. 11, pp. 151-160, 2019.

[67]. D. S. Al-Omairi, W. H. AlNasheri, W. Y. AlQarni, I. Almarashdeh, M. k. Alsmadi, M. Alshabanah, and D. Alrajhi, "Developing and Implementing A Web-Based Recycling System For Protecting The Green Environment," International Journal of Software Engineering and Applications, vol. 10, pp. 59-72, 2019.

[68].E. Alomari, M. Alshammry, S. Alhamil, M. Alsmadi, M. Alshabanah, D. Alrajhi, I. Almarashdeh, and L. Eljawad, "Analyzing, Designing and Implementing a Consulting Company for Management Information Systems," International Research Journal of Engineering and Technology, vol. 6, pp. 422-432, 2019.

[69].E. Alomari, M. Alshammry, S. Alhamil, M. k. Alsmadi, M. Alshabanah, D. Alrajhi, I. Almarashdeh, and L. Eljawad, "Analyzing, Designing and Implementing a Consulting Company for Management Information Systems," International Research Journal of Engineering and Technology vol. 6, pp. 422-432, 2019.

[70].A. M. Al-Smadi, M. K. Alsmadi, A. Baareh, I. Almarashdeh, H. Abouelmagd, and O. S. S. Ahmed, "Emergent situations for smart cities: a survey," International Journal of Electrical \& 
Computer Engineering (2088-8708), vol. 9, pp. 4777-4787, 2019.

[71]. M. K. Alsmadi, "Hybrid Genetic Algorithm with Tabu Search with Back-Propagation Algorithm for Fish Classification: Determining the Appropriate Feature Set," International Journal of Applied Engineering Research, vol. 14, pp. 4387-4396, 2019.

[72]. M. K. Alsmadi, M. Tayfour, R. A. Alkhasawneh, U. Badawi, I. Almarashdeh, and F. Haddad, "Robust feature extraction methods for general fish classification," International Journal of Electrical \& Computer Engineering (2088-8708), vol. 9, pp. 5192-5204, 2019.

[73]. R. Al-Theeb, H. Al-Tami, H. Al-Johani, A. AlMutairi, I. Al-Marashdeh, M. K. Alsmadi, M. Alshabanah, and D. Alrajhi, "Developing and Implementing A System for Shipping Companies Comparison," IJSRST vol. 6, 2019.

[74].H. Alzamel, M. Alshabanah, and M. Alsmadi, "Point of Sale (POS) Network with Embedded Fingerprint Biometric Authentication," International Journal of Scientific Research in Science and Technology (IJSRST), vol. 6, pp. 95111, 2019.

[75]. L. Eljawad, R. Aljamaeen, M. K. Alsmadi, I. AlMarashdeh, H. Abouelmagd, S. Alsmadi, F. Haddad, R. A. Alkhasawneh, M. Alzughoul, and M. B. Alazzam, "Arabic Voice Recognition Using Fuzzy Logic and Neural Network," International Journal of Applied Engineering Research, vol. 14, pp. 651-662, 2019.

[76].F. Haddad, M. K. Alsmadi, U. Badawi, T. Farag, R. Alkhasawneh, I. Almarashdeh, and W. Hassan, "Bivariate modified hotelling's $\mathrm{T}^{2}$ charts using bootstrap data," International Journal of Electrical \& Computer Engineering (2088-8708), vol. 9, pp. 4721-4727, 2019.

[77]. A. S. S. Mohammed, G. M. Alhaj, A. M. Osman, and A. O. Ahmed, "The Effectiveness of the Decision Making of the Saudi Arabian
Universities Applied Colleges' Faculties Boards and Departmental Councils," International Journal of Applied Engineering Research, vol. 14, pp. 4221-4227, 2019.

[78]. A. M. Osman, A. O. Ahmed, M. N. Eltahir, A. S. Mohamed, O. S. Shidwan, and M. Ghada, "Investigating the Causes of inflation in Saudi Arabia: An Application of Autoregressive Distributed Lag (ARDL) Model," International Journal of Applied Engineering Research, vol. 14, pp. 3980-3986, 2019.

[79].Y. K. Qawqzeh, M. M. Otoom, F. Al-Fayez, I. Almarashdeh, M. Alsmadi, and G. Jaradat, "A Proposed Decision Tree Classifier for Atherosclerosis Prediction and Classification," IJCSNS, vol. 19, p. 197, 2019.

[80].R. A. Sheikh, R. Al-Assami, M. Albahr, M. A. Suhaibani, M. k. Alsmadi, M. Alshabanah, D. Alrajhi, I. Al-Marashdeh, S. Alsmadi, H. Abouelmagd, and M. Tayfour, "Developing and Implementing a Barcode Based Student Attendance System," International Research Journal of Engineering and Technology, vol. 6, pp. 497-506, 2019.

[81].M. K. Alsmadi, "Content-Based Image Retrieval Using Color, Shape and Texture Descriptors and Features," Arabian Journal for Science and Engineering, pp. 1-14, 2020.

[82].M. A. Alzaqebah, N. Alrefai, E. Ahmed, S. Jawarneh, and M. Alsmadi, "Neighborhood search methods with Moth Optimization algorithm as a wrapper method for feature selection problems," International Journal of Electrical \& Computer Engineering, vol. 10, 2020.

[83].Y. K. Qawqzeh, G. Jaradat, A. AlYousef, A. AbuHamdah, I. Almarashdeh, M. Alsmadi, M. Tayfour, K. Shaker, and F. Haddad, "Applying the Big Bang-Big Crunch Metaheuristic to Largesized Operational Problems," International 
Journal of Electrical and Computer Engineering, vol. 10, pp. 2484-2502, 2020.

[84]. M. Barrett, J. Boyne, J. Brandts, H.-P. BrunnerLa Rocca, L. De Maesschalck, K. De Wit, L. Dixon, C. Eurlings, D. Fitzsimons, O. Golubnitschaja, A. Hageman, F. Heemskerk, A. Hintzen, T. M. Helms, L. Hill, T. Hoedemakers, N. Marx, K. McDonald, M. Mertens, D. MüllerWieland, A. Palant, J. Piesk, A. Pomazanskyi, J. Ramaekers, P. Ruff, K. Schütt, Y. Shekhawat, C. F. Ski, D. R. Thompson, A. Tsirkin, K. van der Mierden, C. Watson, and B. Zippel-Schultz, "Artificial intelligence supported patient selfcare in chronic heart failure: a paradigm shift from reactive to predictive, preventive and personalised care," The EPMA journal, vol. 10, pp. 445-464, 2019.

[85].S. Ellahham, N. Ellahham, and M. C. E. Simsekler, "Application of Artificial Intelligence in the Health Care Safety Context: Opportunities and Challenges," American Journal of Medical Quality, p. 1062860619878515, 2019.

[86]. M. Fontoura, W. Pree, and B. Rumpe, "UML-F: A modeling language for object-oriented frameworks," in European Conference on Object-Oriented Programming, 2000, pp. 63-82.

[87].1. Teixeira, A. R. Xambre, J. Figueiredo, and H. Alvelos, "Analysis and design of a project management information system: practical case in a consulting company," in CENTERIS/ProjMAN/HCis, 2016, pp. 171-178.

[88]. I. Almarashdeh, N. F. Elias, N. Sahari, and N. A. M. Zain, "Development of an interactive learning management system for malaysian distance learning institutions. ," Middle East Journal of Scientific Research, 14(11), . 10.5829/idosi.mejsr.2013.14.11.2339, vol. 14, pp. 1471-1479, 2013.

[89]. D. Rajagopal and K. Thilakavalli, "A Study: UML for OOA and OOD," International Journal of
Knowledge Content Development \& Technology, vol. 7, pp. 5-20, 2017.

[90]. M. Torchiano, G. Scanniello, F. Ricca, G. Reggio, and M. Leotta, "Do UML object diagrams affect design comprehensibility? Results from a family of four controlled experiments," Journal of Visual Languages \& Computing, vol. 41, pp. 10-21, 2017/08/01/ 2017.

[91].S. I. Bello, R. O. Bello, A. O. Babatunde, M. Olugbebi, and B. O. Bello, "A University Examination Web Application Based on LinearSequential Life Cycle Model," 2017.

[92]. I. Almarashde, A. Althunibat, and N. Fazidah El, "Developing a Mobile Portal Prototype for Egovernment Services," Journal of Applied Sciences, vol. 14, pp. 791-797, 2014.

[93].R. Ibrahim, "Formalization of the data flow diagram rules for consistency check," arXiv preprint arXiv:1011.0278, 2010.

[94]. N. A. Nora Alsubaie, Eman Alradwan, Fatima Al-Hazza, Mutasem Alsmadi, Ibrahim AlMarashdeh, Usama A Badawi, Muneerah Alshabanah, Daniah Alrajhi, Sanaa Alsmadi, Mohammed Tayfour., "Analyzing and Implementing an Online Metro Reservation System," International Journal of Applied Engineering Research, vol. 13, pp. 9198-9206, 2018.

Cite this article as : Nada Abdullah Alqarni, Shahad Saeed Alqahtani, Sara Ahmed Alhumaidi, Ibtihaj Mohammed Almutairi, Muneerah Alshabanah, Daniah Alrajhi, Mutasem K. Alsmadi, Ibrahim Almarashdeh, "Developing a Platform for Chronic Diseases Awareness", International Journal of Scientific Research in Science and Technology (IJSRST), Online ISSN : 2395-602X, Print ISSN : 23956011, Volume 7 Issue 2, pp. 147-158, March-April 2020. Available at doi : https://doi.org/10.32628/IJSRST207160 Journal URL : http://ijsrst.com/IJSRST207160 